ORIGINAL ARTICLE

\title{
Outcome of HIV infected children with culture confirmed tuberculosis
}

\author{
A C Hesseling, A E Westra, H Werschkull, P R Donald, N Beyers, G D Hussey, \\ W El-Sadr, H Simon Schaaf
}

See end of article for authors' affiliations

Correspondence to:

Dr A Hesseling, Desmond Tutu TB Centre, Faculty of Health Sciences,

Stellenbosch University, PO Box 19063,

Tygerberg, 7505, South Africa; annekeh@sun.ac. za

Accepted 31 May 2005 Published Online First 17 June 2005

Background: Tuberculosis (TB) is an important disease in human immunodeficiency virus (HIV) infected children living in regions where TB is endemic. There are limited data on the outcome of culture confirmed TB in HIV infected children.

Aims and Methods: To describe the outcome on TB therapy and overall mortality in HIV infected children with culture confirmed TB through a retrospective cohort study.

Results: Eighty seven children, median age 24 months, contributed to 93 TB episodes; six children had two confirmed episodes. Pulmonary disease (PTB) was present in 71 episodes (76.3\%), extrapulmonary disease (EPTB) in 43 (46.2\%), and of these, both PTB and EPTB were present in 21 (22.6\%). There was cure based on bacteriological and/or radiological criteria in 54 episodes (58.1\%). Eighteen children died during TB therapy and there were a total of 34 deaths (39.1\%). In univariate analysis ( $n=87$ patients), severe malnutrition, age $\leqslant 1$ year, and a negative tuberculin skin test were significant risk factors for death during TB therapy. In multivariate survival analysis ( $n=87$ patients), HIV disease category, severe malnutrition at diagnosis, and lack of cure at the end of TB therapy were significantly associated with overall mortality.

Conclusion: In the absence of antiretroviral therapy, HIV infected children with confirmed TB have poor outcomes on antituberculosis therapy and are at high risk of death during and after completion of antituberculosis therapy, especially due to non-TB related causes. There is an urgent need to optimise and monitor antituberculosis therapy in HIV infected children and to improve access to TB and other preventative therapy.

$\mathrm{H}$ uman immunodeficiency virus (HIV) infected children are at increased risk for tuberculosis (TB). ${ }^{1}$ Previous reports suggest that HIV infected children respond poorly to antituberculosis therapy compared with HIV uninfected children. ${ }^{2-5}$ We describe outcome during antituberculosis therapy and overall mortality in HIV infected children with culture confirmed TB in an area with endemic TB and HIV.

\section{METHODS}

This retrospective cohort study assessed all children $\leqslant 13$ years of age with confirmed HIV infection and culture confirmed tuberculosis, hospitalised from January 1992 to December 2000 and from January 1998 to December 2000, respectively, at two referral centres in the Western Cape Province, South Africa. Antiretroviral therapy was unavailable in the public health sector.

TB disease was confirmed by isolation of Mycobacterium tuberculosis from any source in the presence of symptoms, and HIV infection by enzyme linked immunosorbent assay (ELISA) and polymerase chain reaction or detection of p24 antigen in children $\leqslant 15$ months of age. HIV disease was staged according to Centers for Disease Control criteria. ${ }^{6}$

TB treatment included six month regimens of three (isoniazid, rifampicin, and pyrazinamide) or four drugs (ethambutol or ethionamide added), according to national guidelines. On discharge, children completed clinic based directly observed therapy.

Clinical information was collected through patient chart review. Severe protein energy malnutrition (PEM) was defined according to the Wellcome classification (marasmus and/or kwashiorkor): a negative tuberculin skin test (TST) as a Mantoux test of $\leq 5 \mathrm{~mm}$ or Tine test with papules indurated $\leqslant 2 \mathrm{~mm}$. Chest radiographs were read according to a standardised method by two independent readers. ${ }^{7}$

Outcome, including cure and death during TB therapy, and total mortality at the end of the study period, were assessed. Cure was defined as culture negativity at therapy completion and/or radiological improvement of chest radiographic features. All children were followed through July 2002 or until lost to follow up, after deliberate attempts at tracing them at this point through local clinics, home visits or telephone calls. If lost to follow up, the date last seen was recorded.

Data were analysed using SPSS (version 11.5). Descriptive analyses for clinical characteristics were done for $n=93$ episodes by HIV stage, and outcomes for $n=87$ patients. Kaplan-Meier and Cox proportional hazard modelling compared long term survival by HIV stage; patients lost to follow up were censored. The study was approved by the ethics committee of the Faculty of Health Sciences, Stellenbosch University.

\section{RESULTS}

Eighty seven children were eligible for the study; all were included in analysis, representing 93 TB episodes: 2 children with HIV stage A, 30 stage $B$, and 55 stage $C$ disease. Two children died before initiation of TB therapy. No children were lost to follow up during therapy. The median treatment duration was 6 months (mean 7.2 months; $p=0.352$ ) and mean number of antituberculosis drugs 3.3; three children had undocumented adherence or defaulted on TB therapy.

Abbreviations: EPTB, extrapulmonary tuberculosis; HIV, human immunodeficiency virus; PEM, protein energy malnutrition; PTB, pulmonary tuberculosis; TB, tuberculosis; TST, tuberculin skin test 


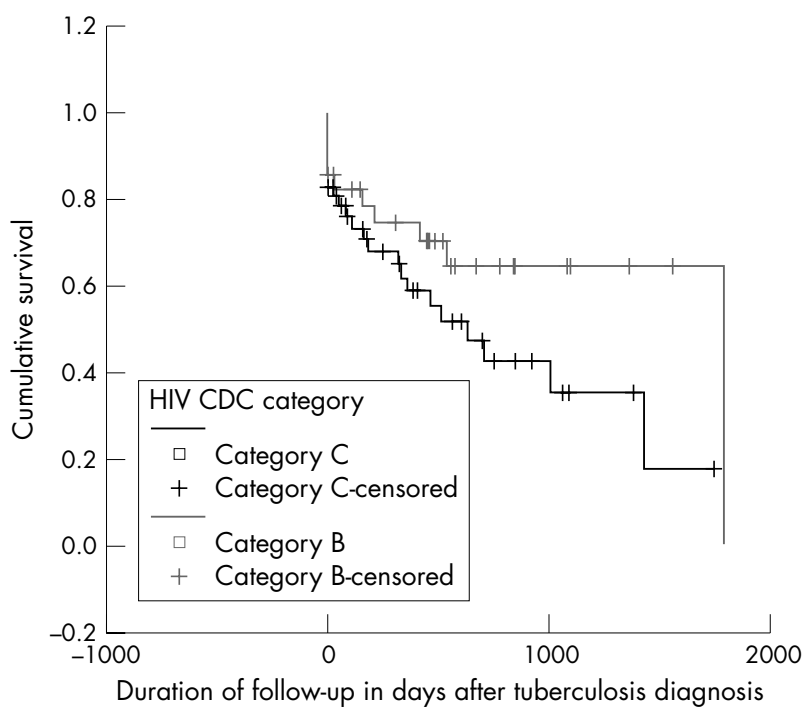

Figure 1 Kaplan-Meier curve of survival by HIV CDC stage. -2 log likelihood ratio, $p=0.1327$. CDC, Centers for Disease Control Classification. ${ }^{6}$

\section{Patient characteristics}

Age at TB diagnosis ranged from 1 to 158 months (median 24); age at HIV diagnosis ranged from 1 to 98 months (median 17) (table 1). Drug resistance was detected in 9
(15.5\%) of 58 TB episodes (62.3\% tested); 5 (8.6\%) had multidrug resistance. A TST, performed and read in 78 episodes $(83.9 \%)$, was positive in $44(56.4 \%)$.

The dominant findings on chest radiography were mediastinal adenopathy in 56 episodes (60.2\%), and lobar/ segmental opacification in $51(54.8 \%)$. There was severe pulmonary disease, defined as $\geqslant 1$ of the following: miliary disease, cavities, bronchopneumonic opacification, or lobar disease involving $\geqslant 2$ lobes, in 55 episodes $(59.2 \%, p=0.169)$. CD4+ T lymphocyte count at diagnosis $\leqslant 15 \%$ was significantly associated with miliary disease $(p=0.05)$; however, CD4+ T lymphocyte count data was incomplete (missing data in $45.2 \%)$.

\section{Outcome during antituberculosis therapy}

Bacteriologic cure was confirmed in $44 / 56$ episodes (78.6\%) where cultures were repeated and in 44/93 total episodes $(47.3 \%)$ (table 2). There was radiological improvement of TB features in $30(32.3 \%)$, partial or no improvement in 40 $(43 \%)$, and missing data in $23(24.7 \%)$ episodes. There was cure based on a combination of bacteriological and/or radiological criteria in 54 episodes $(58.1 \%$; missing data in 13; 14\%). Mycobacterium tuberculosis was isolated in 12 episodes $(13 \%) \geqslant 6$ months after treatment initiation: in eight episodes with HIV stage B and in four with stage C disease $(p=0.565)$. These children were all treatment adherent; none showed chest radiographic improvement at $\geqslant 6$ months after initiation of therapy and none had drug resistance.

Table 1 Characteristics in children with HIV at culture confirmed tuberculosis diagnosis ( $\mathrm{n}=93$ episodes)

\begin{tabular}{|c|c|c|c|c|}
\hline & $\begin{array}{l}\text { Total } \\
\mathrm{n}=93(\%)\end{array}$ & $\begin{array}{l}\text { CDC HIV stage B } \\
n=35(\%)\end{array}$ & $\begin{array}{l}\text { CDC HIV stage C } \\
n=58(\%)\end{array}$ & p value \\
\hline \multicolumn{5}{|l|}{ Demographic features } \\
\hline Mean age at TB diagnosis $†$ & 32.62 & 33.40 & 32.16 & $0.740^{*}$ \\
\hline Close adult contact & $57(61.3)$ & $24(68.6)$ & $33(56.9)$ & 0.239 \\
\hline MDR contact & $2(2.2)$ & $0(0)$ & $2(3.4)$ & 0.323 \\
\hline Previous TB therapy & $14(15.1)$ & $6(17.1)$ & $8(13.8)$ & 0.418 \\
\hline Previous TB prophylaxis & $15(16.1)$ & $8(22.9)$ & $7(12.1)$ & 0.125 \\
\hline \multicolumn{5}{|l|}{ Clinical characteristics } \\
\hline Documented BCG/scarring & $58(62.4)$ & $20(57.1)$ & $38(65.5)$ & 0.730 \\
\hline Severe PEM & $23(24.7)$ & $4(11.4)$ & 19 (32.8) & $0.017^{* *}$ \\
\hline Weight for age $<3$ centile & 44 (47.3) & $20(57.1)$ & $24(41.4)$ & 0.104 \\
\hline Peripheral lymphadenopathy & $84(90.3)$ & $30(85.7)$ & $54(93.1)$ & 0.497 \\
\hline Fever & $68(73.1)$ & $25(71.4)$ & $43(74.1)$ & 0.479 \\
\hline Cough $>2$ weeks & $59(63.4)$ & $24(68.6)$ & $35(60.3)$ & 0.284 \\
\hline Digital clubbing & $26(28.0)$ & $12(34.3)$ & $14(24.1)$ & 0.206 \\
\hline Respiratory distress (tachypnoeic) & $65(69.9)$ & $23(65.7)$ & $42(72.4)$ & 0.325 \\
\hline Sputum microscopy positive & $\begin{array}{l}29 / 76 \text { done } \\
(38.0)\end{array}$ & $\begin{array}{l}11 / 28 \text { done } \\
(39.0)\end{array}$ & $\begin{array}{l}18 / 48 \text { done } \\
(37.5)\end{array}$ & 0.877 \\
\hline Tuberculin skin test negative & $\begin{array}{l}34(43.6) \\
n=78 \text { done } \\
(83.9)\end{array}$ & $\begin{array}{l}6(21.4) \\
n=28 \text { done } \\
(80.0)\end{array}$ & $\begin{array}{l}28(56.0) \\
n=50 \text { done } \\
(86.2)\end{array}$ & $0.003^{* *}$ \\
\hline CD4 T lymphocyte $\leqslant 15 \%$ & $\begin{array}{l}21(41.2) \\
n=51 \text { done } \\
(54.8)\end{array}$ & $\begin{array}{l}10(47.6) \\
n=18 \text { done } \\
(51.0)\end{array}$ & $\begin{array}{l}11(52.4) \\
n=33 \\
(56.9)\end{array}$ & 0.107 \\
\hline \multicolumn{5}{|l|}{ Tuberculosis characteristics } \\
\hline PTB & $71(76.3)$ & $32(91.4)$ & $39(67.2)$ & $0.006^{* *}$ \\
\hline EPTB & $43(46.2)$ & $5(11.6)$ & $38(88.4)$ & $<0.001^{* *}$ \\
\hline PTB and EPTB & $21(22.6)$ & $4(11.4)$ & $17(29.3)$ & $0.038^{* *}$ \\
\hline Miliary TB & $21(22.6)$ & $6(17.1)$ & $15(25.9)$ & 0.238 \\
\hline Cavitating TB & $20(21.5)$ & $9(45.0)$ & $11(55.0)$ & 0.303 \\
\hline Mono-drug resistant TB & $9(9.7)$ & $4(11.4)$ & $5(8.6)$ & 0.450 \\
\hline MDR TB & $5(5.4)$ & $2(5.7)$ & $3(5.2)$ & 0.626 \\
\hline
\end{tabular}

CDC HIV stage: Centers for Disease Control and Prevention. ${ }^{6}$ All missing data were excluded from analysis. As there were only two children with stage A disease, CDC HIV categories A and B were combined for analysis purposes $(n=32)$. Analyses performed with and without disease category $A$ were identical. $\dagger$ Age in months. *Student's $t$ test. **Statistically significant; all $p$ values reported are one sided exact $p$ values, $\chi^{2}$ statistic, or Fishers' exact test. MDR, multidrug resistant tuberculosis; TB, tuberculosis; HIV, human immunodeficiency virus; BCG, bacille Calmette-Guerin; TST, tuberculin skin test; PEM, marasmus/kwashiorkor according to the Wellcome classification; Peripheral adenopathy, HIV related persistent generalised lymphadenopathy; Respiratory distress, tachypnoeic; Cavitating TB, cavities noted on chest radiograph; Miliary TB, exclusive miliary opacification on chest radiography that improved on antituberculosis therapy; PTB, pulmonary tuberculosis; EPTB, extrapulmonary tuberculosis; Sputum microscopy, Ziehl-Nielsen microscopy for acid-fast bacilli. 
Table 2 Outcomes of culture confirmed tuberculosis in HIV infected children ( $\mathrm{n}=93$ episodes; $\mathrm{n}=87$ patients)

\begin{tabular}{|c|c|c|c|c|}
\hline TB episodes $(n=93$ ) & $\begin{array}{l}\text { Total } \\
n=93(\%)\end{array}$ & $\begin{array}{l}\text { HIV CDC stage B } \\
n=35(\%)\end{array}$ & $\begin{array}{l}\text { HIV CDC stage C } \\
n=58(\%)\end{array}$ & p value* \\
\hline Culture negative & $\begin{array}{l}44 / 93(47.3) \\
n=56 \text { done }(60.2)\end{array}$ & $\begin{array}{l}16 / 35(45.7) \\
n=20 \text { done } \\
(57.1)\end{array}$ & $\begin{array}{l}28 / 58(48.3) \\
n=36 \text { done } \\
(62.1)\end{array}$ & 0.565 \\
\hline Radiological improvement & $\begin{array}{l}30 / 93 \text { (32.2) } \\
n=70 \text { done } \\
(75.3)\end{array}$ & $\begin{array}{l}9 / 35(25.7) \\
n=22 \text { done } \\
(62.9)\end{array}$ & $\begin{array}{l}21 / 58(36.2) \\
n=48 \text { done } \\
(82.8)\end{array}$ & 0.824 \\
\hline Bacteriological and/or radiological cure & $\begin{array}{l}54 / 93(58.1) \\
n=80 \text { done } \\
(86.0)\end{array}$ & $\begin{array}{l}19 / 35(54.3) \\
n=28 \text { done } \\
(80.0)\end{array}$ & $\begin{array}{l}35 / 58(60.3) \\
n=52 \text { done } \\
(89.7)\end{array}$ & 0.583 \\
\hline Severe PEM at therapy completion & $12 / 93(12.9)$ & $1 / 35(2.9)$ & $11 / 58(19.0)$ & $0.021^{* *}$ \\
\hline $\begin{array}{l}\text { TB patients }(n=87) \\
\text { Death on TB therapy } \\
\text { Total deaths } \\
\text { Lost to follow up } \\
\text { Further confirmed TB episode }\end{array}$ & $\begin{array}{l}\mathbf{n}=87(\%) \\
18(20.7) \\
34(39.1) \\
13(14.9) \\
6(6.9)\end{array}$ & $\begin{array}{l}\mathbf{n}=32(\%) \\
4(12.5) \\
10(31.3) \\
6(18.8) \\
3(9.4)\end{array}$ & $\begin{array}{l}\mathbf{n}=55(\%) \\
14(25.5) \\
24(43.6) \\
7(12.7) \\
3(5.5)\end{array}$ & $\begin{array}{l}0.107 \\
0.181 \\
0.322 \\
0.405\end{array}$ \\
\hline \multicolumn{5}{|c|}{$\begin{array}{l}\text { CDC HIV stage: Centers for Disease Control and Prevention. }{ }^{6}{ }^{*} \chi^{2} \text { statistic, one sided exact } p \text { value. }{ }^{* *} \text { Statistically significant, Fisher's exact test. } \\
\text { Missing data for } n=93 \text { episodes: culture negative, } 36 / 93(41.9 \%) \text {; radiological improvement, } 23(24.7 \%) \text {; combined bacteriological and/or radiological cure, } \\
13 / 93 \text { (14\%). All other data are complete. } \\
\text { Lost to follow up: lost to follow up after completion of TB therapy as measured at the end of the study period (July 2002). Total deaths: deaths during TB episode } \\
\text { therapy and after completion of therapy until lost to follow up or at the end of study period. }\end{array}$} \\
\hline
\end{tabular}

There were 18 deaths during TB therapy: four in children with HIV stage B and 14 with stage $C$ disease $(p=0.107)$; median duration until death 116 days. Four deaths $(22.2 \%)$ occurred within two months following treatment initiation. Two children died before therapy was initiated, one due to Pneumocystic jivoveci pneumonia (PCP) and the other to bacterial septicaemia. In univariate analysis, age $\leqslant 1$ year $(\mathrm{p}=0.002)$, severe PEM at diagnosis $(\mathrm{p}=0.009)$, and a negative TST $(\mathrm{p}=0.009)$ were significantly associated with mortality during therapy.

Outcome after completion of antituberculosis therapy Sixteen deaths occurred after antituberculosis therapy completion. There were $34(39.1 \%)$ total deaths: 10 in children with HIV stage B and 24 in stage C disease $(\mathrm{p}=0.181)$. Thirteen children $(14.9 \%)$ were lost to follow up after treatment completion. TB accounted for $17.6 \%$ of deaths, including multidrug resistant disease $(3 ; 8.8 \%)$, TB meningitis $(2 ; 5.8 \%)$ and miliary disease $(1 ; 2.9 \%)$. Non-TB deaths were attributed to bacterial pneumonia and/or septicaemia in $13(38.2 \%)$, severe AIDS wasting in two
(5.9\%), severe gastroenteritis in two $(5.9 \%)$, PCP in two $(5.9 \%)$, HIV encephalopathy in one $(2.9 \%)$, disseminated varicella in one $(2.9 \%)$, disseminated BCG disease in one $(3.6 \%)$, and undocumented causes in six (17.6\%).

Kaplan-Meier analysis of all deaths over total follow up in days (range 6-3730, median 3602 days) showed no significant differences between HIV disease stages (-2 log likelihood ratio, $\mathrm{p}=0.1327$ ) ( see fig 1 ). In multivariate Cox survival analysis, HIV disease category, severe PEM at diagnosis, and lack of cure at end of TB therapy were significantly associated with overall mortality (table 3 ).

Fourteen children $(16.1 \%)$ were retreated after treatment completion; in six $(42.9 \%)$ there was bacterial confirmation by culture.

\section{DISCUSSION}

The most important findings of this study are the poor outcomes of HIV infected children with culture confirmed TB on antituberculosis therapy in the absence of antiretroviral therapy and the high mortality during antituberculosis therapy and at follow up. Most deaths were not directly

Table 3 Cox proportional hazards survival model of total deaths according to HIV stage and other covariates in HIV infected children with culture confirmed tuberculosis $(n=34$ total deaths)

\begin{tabular}{|c|c|c|c|c|}
\hline & \multirow[b]{2}{*}{ Rate ratio } & \multirow[b]{2}{*}{ Significance* } & \multicolumn{2}{|c|}{$95 \% \mathrm{Cl}$ for rate ratios } \\
\hline & & & Lower & Upper \\
\hline $\begin{array}{l}\text { Crude estimates } \\
\text { HIV CDC stage C } † \\
\text { Severe PEM } \\
\text { TST negative } \\
\text { Age } \leqslant 1 \text { year } \\
\text { Not cured }\end{array}$ & $\begin{array}{l}2.416 \\
2.636 \\
2.303 \\
1.505 \\
3.717\end{array}$ & $\begin{array}{l}0.088 \\
0.046^{* *} \\
0.092 \\
0.430 \\
0.010^{* *}\end{array}$ & $\begin{array}{l}0.877 \\
1.019 \\
0.874 \\
0.545 \\
1.370\end{array}$ & $\begin{array}{r}6.656 \\
6.821 \\
6.068 \\
4.155 \\
10.085\end{array}$ \\
\hline $\begin{array}{l}\text { Adjusted estimates } \\
\text { HIV CDC stage C } † \\
\text { Severe PEM } \\
\text { TST negative } \\
\text { Age } \leqslant 1 \text { year } \\
\text { Not cured }\end{array}$ & $\begin{array}{r}7.877 \\
3.944 \\
1.923 \\
0.687 \\
11.870\end{array}$ & $\begin{array}{l}0.014^{* *} \\
0.028^{* *} \\
0.301 \\
0.607 \\
<0.001^{* *}\end{array}$ & $\begin{array}{l}1.523 \\
1.1517 \\
0.557 \\
0.164 \\
3.126\end{array}$ & $\begin{array}{r}40.731 \\
13.444 \\
6.639 \\
2.878 \\
45.072\end{array}$ \\
\hline $\begin{array}{l}\text { *Wald statistic. }{ }^{* *} \text { St } \\
\text { †Centers for Diseas } \\
\text { TST, tuberculin skin } \\
\text { cured, lack of cultur } \\
\text { tuberculosis. }\end{array}$ & $\begin{array}{l}\text { gnificant. } \\
\text { ind Prevent } \\
\text { PEM, mar } \\
\text { n at six mo }\end{array}$ & $\begin{array}{l}\text { d/or kwashio } \\
\text { /or marked ro }\end{array}$ & $\begin{array}{l}\text { Iccording } \\
\text { jical imp }\end{array}$ & $\begin{array}{l}\text { me classification; Not } \\
\text { f features classified as }\end{array}$ \\
\hline
\end{tabular}




\section{What is already known on this topic}

- HIV infected children have a poor response to standard antituberculosis therapy

- HIV infected children with culture confirmed tuberculosis have a high mortality

\section{What this study adds}

- HIV infected children with advanced HIV disease, severe malnutrition, and incomplete cure at the end of antituberculosis therapy are at greatest risk of death; death is mainly due to acute opportunistic infections

- HIV infected children with culture confirmed tuberculosis have a high risk of recurrent tuberculosis

tuberculosis related but due to acute opportunistic infections. Children with advanced HIV disease, severe malnutrition, and incomplete cure at the end of TB therapy were at greatest risk. There was a higher proportion of extrapulmonary $\mathrm{TB}$ noted in children with more advanced HIV disease; however cause and effect are difficult to distinguish.

The confirmation of cure in childhood paucibacillary disease is difficult without bacteriologic proof. In children where repeat cultures were not available at the end of therapy, we relied on improvement of chest radiographic features. The high proportion where no substantial improvement was noted may indicate inadequate treatment response, and/or the co-prevalence of other chronic lung disease. However, in children where failure of bacteriological cure was documented, chest radiographic lesions indicative of TB had similarly not improved. The high proportion of children with persistent positive cultures six months or more after initiation of therapy while adherent, suggests suboptimal treatment response.

This study has limitations: the confounding effects of HIV on TB presentation and TST, the limitations of chest radiograph interpretation in HIV infected children, the study's retrospective nature, incomplete data on CD4+ T lymphocyte counts, the lack of postmortem examination data, and possible inadequate control for adherence to antituberculosis therapy. However, in this large cohort, despite limited resources, diagnosis was confirmed by culture in all children, and follow up was achieved with chest radiograph and/or culture in the majority.

In summary, there is an urgent need to assess therapeutic and preventative strategies, including antiretroviral and preventative therapy aimed at TB and other opportunistic infections, to improve treatment outcome, and reduce mortality in this vulnerable group.

\section{ACKNOWLEDGEMENTS}

We acknowledge the Department of Science and Technology through Technology and Human Resources for Industry Programme, South Africa (THRIP) for funding to ACH, and the Nestle Community Research Fund for financial support.

\section{Authors' affiliations}

A C Hesseling, P R Donald, N Beyers, H Simon Schaaf, Stellenbosch University, Cape Town, South Africa

A E Westra, H Werschkull, University of Amsterdam, Netherlands G D Hussey, University of Cape Town, South Africa

W El-Sadr, Columbia University, New York

Competing interests: none

\section{REFERENCES}

1 Cotton MF, Schaaf HS, Hesseling AC, et al. HIV and childhood tuberculosisthe way forward. Int J Tuberc Lung Dis 2004;8:675-82.

2 Mukadi YD, Wiktor SZ, Coulibaly IM, et al. Impact of HIV infection on the development, clinical presentation, and outcome of tuberculosis among children in Abidjan, Cote d'Ivoire. AIDS 1997;1:1151-8.

3 Graham SM, Coulter JB, Gilks CF. Pulmonary disease in HIV-infected African children. Int J Tuberc Lung Dis 2001;5:12-23.

4 Jeena PM, Mitha T, Bamber A, et al. Effect of human immunodeficiency virus on tuberculosis in children. Tuberc Lung Dis 1996;77:437-43.

5 Espinal MA, Reingold AL, Perez G, et al. Human immunodeficiency virus infection in children with tuberculosis in Santo Domingo, Dominican Republic: prevalence, clinical findings, and response to antituberculosis treatment. J Acquir Immune Defic Syndr Hum Retrovirol 1996;13:155-9.

6 Centers for Disease Control and Prevention. 1994 Revised classification system for human immunodeficiency virus infection in children less than 13 years of age. MMWR Morb Mortal Wkly Rep 1994;43:1-10.

7 Smuts NA, Beyers N, Gie RP, et al. Value of the lateral chest radiograph in tuberculosis in children. Pediatr Radiol 1994;24:478-80. 